\title{
The dynamic behavior of moving rectangular liquid filling
}

\author{
KAMILA KOTRASOVÁ ${ }^{1}$, EVA KORMANÍKOVÁ ${ }^{1}$, SLÁVKA HARABINOVÁ ${ }^{1}$, MOHAMED \\ LOUKILI $^{2}$ \\ ${ }^{1}$ Institute of Structural Engineering \\ Technical University of Kosice \\ Vysokoškolská 4, 04200 Košice \\ SLOVAKIA \\ ${ }^{2}$ Department of Physics \\ Hassan II University of Casablanca \\ Faculty of Sciences Ben M'sik, P.O. BOX 7955, Casablanca \\ MOROCCO
}

\begin{abstract}
This paper is revolved around analyzing the dynamic behavior of the liquid filling in the various moving rectangular reservoirs. For sake of clarity, when the contained liquid vibrates, the liquid exerts the hydrodynamic pressure on the reservoir. Then, the theoretical background of the total and hydrodynamic pressure on the rectangular reservoir is described. Thereafter, our interest is to perform to the experimental and numerical analysis associated with the behavior of moving rectangular liquid filling.
\end{abstract}

Key-Words: - liquid, rectangular tank, moving, pressure, frequency, experiment

Received: June 15, 2020. Revised: November 7, 2020. Accepted: November 19, 2020. Published: November 29, 2020.

\section{Introduction}

The dynamic behavior of the liquid filling in the different kind of moving reservoirs is the interesting subject for investigation [1]. The liquid sloshing in of moving liquid-containing or liquid-transporting structures is conjugated with the various technical problems and the understanding of the sloshing mechanism is very important $[2,3]$. The sloshing is the oscillation of the liquid mass in moving engineering storage structures, and it is characteristically by the wave motion from one side to other side within the container [4-6]. When the frequency of the container motion is close to the natural frequency of the liquid filling, then the sloshing answer is the extreme and the extreme liquid movement can cause the high local impact loads on the storage structures [7-12].

The liquid is characterized by the different types of motion [13]: simple planar, non-planar, rotational, irregular beating, symmetric, asymmetric, quasiperiodic, chaotic. The types of the motion are depending on the shape of the storage structure and the type of the excitation [14-18]. The amplitude of the slosh depends on the liquid-fill dimensions, the properties of liquid, the geometry of storage structure, the excitation frequency, and the excitation amplitude [19].
The liquid splashing plays important role for the reliability and safety design of the storage structures, because the eventual damages of storage structures used for storage of hazardous liquids (petroleum, liquefied natural gas, different kind of chemical and radioactive waste) are catastrophic [20]. Potential damage of storage structures and possible leakage of the liquids have far-reaching consequences [21]. They are not only financially but especially environmental degradation [22-25]. The knowledge of the phenomenon of the contained liquid sloshing, the knowledge of dynamic interaction between the contained liquid and the storage structure, the knowledge hydrodynamic effect on solid domain of storage structures, as well as the frequency properties of the liquid and the liquid-structure system plays a decisive basis in designing the storage structure resistant to earthquakes [26].

The behavior of liquid filling in a storage structures has investigated by many researchers and engineers [27]. In 1933, Westergaard had determined the hydrodynamic pressures acting on rectangular dam subjected to horizontal acceleration [28]. The simplified analysis of the hydrodynamic pressure on the tank walls and tank bottom subjected to a horizontal acceleration had investigated by Housner [29], he had established the impulsive and convective components of the hydrodynamic pressure in a rigid 
tank wall by introducing a simplified method of the hydrodynamic analysis in the system tank-liquid and adopting the concept of two dynamic components dynamic impulsive and convective masses. Velestos [28] had also discussed the hydrodynamic pressure on rigid and flexible wall. Haround, Velestos and Malhotra had introduced the mechanical model for the flexible storage structure [28].

\section{Effect of moved liquid-filing due to horizontal acceleration}

In the section, the liquid is considered incompressible, inviscid, by neglecting the gravity force, the liquid motion is described by the Euler equations that are expressed as

$$
\begin{aligned}
& \frac{\partial u}{\partial t}+u \frac{\partial u}{\partial x}+v \frac{\partial u}{\partial y}+w \frac{\partial u}{\partial z}=-\frac{1}{\rho} \frac{\partial p}{\partial x}, \\
& \frac{\partial v}{\partial t}+u \frac{\partial v}{\partial x}+v \frac{\partial v}{\partial y}+w \frac{\partial v}{\partial z}=-\frac{1}{\rho} \frac{\partial p}{\partial y}, \\
& \frac{\partial w}{\partial t}+u \frac{\partial w}{\partial x}+v \frac{\partial w}{\partial y}+w \frac{\partial w}{\partial z}=-\frac{1}{\rho} \frac{\partial p}{\partial z},
\end{aligned}
$$

where $u, v$, and $w$ are the velocity components in the $x, y$, and $z$ directions respectively, $p$ is total pressure, $\rho$ is the density, and $t$ is time [30,31].

When the contained liquid is subjected to horizontal motion, the liquid domain exerts the hydrodynamic pressure together with hydrostatic pressure on tank structure (domain walls and bottom) of groundsupported liquid-containing or liquid-transporting structures [32].

The total pressure of liquid domain is given by the absolute summation rule of the hydrostatic and hydrodynamic pressure

$p(t)=p_{H S}(t)+p_{H D}(t)$.

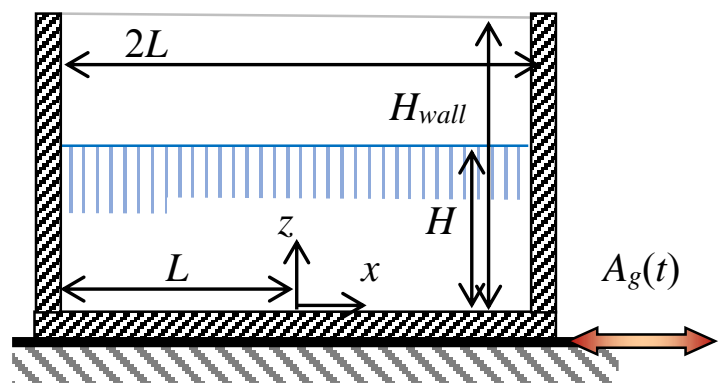

Fig. 1: Rectangular tank

The total hydrodynamic pressure is obtained by the absolute summation rule of the impulsive and the convective pressure

$p_{H D}(t)=p_{i}(t)+\sum_{n=1}^{\infty} p_{c n}(t)$.

\subsection{The hydrodynamic impulsive pressure}

The hydrodynamic impulsive pressure of the contained liquid domain is given on the side vertical wall of the rectangular tank solid domain by

$p_{i w}(\xi, t)=C_{i w}(\xi) \rho H A_{g}(t)$,
$C_{i w}(\xi)=\frac{\sqrt{3}}{2}\left(1-\xi^{2}\right) \tanh \sqrt{3} \frac{L}{H}$.

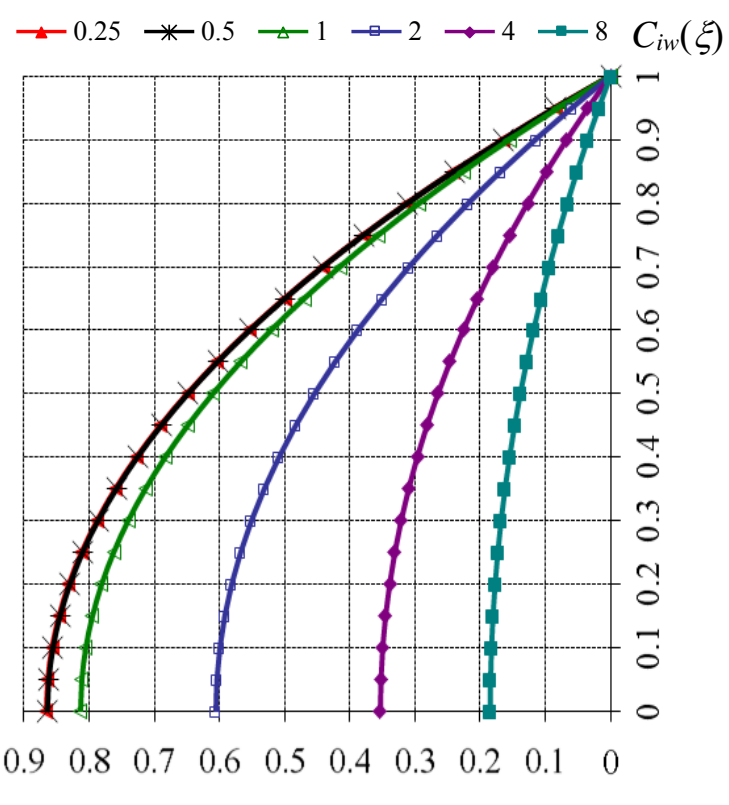

Fig. 2: The function $C_{i w}(\xi)$ of the impulsive wall pressures distribution of liquid for various reservoir slenderness parameter $\gamma$ of liquid filling

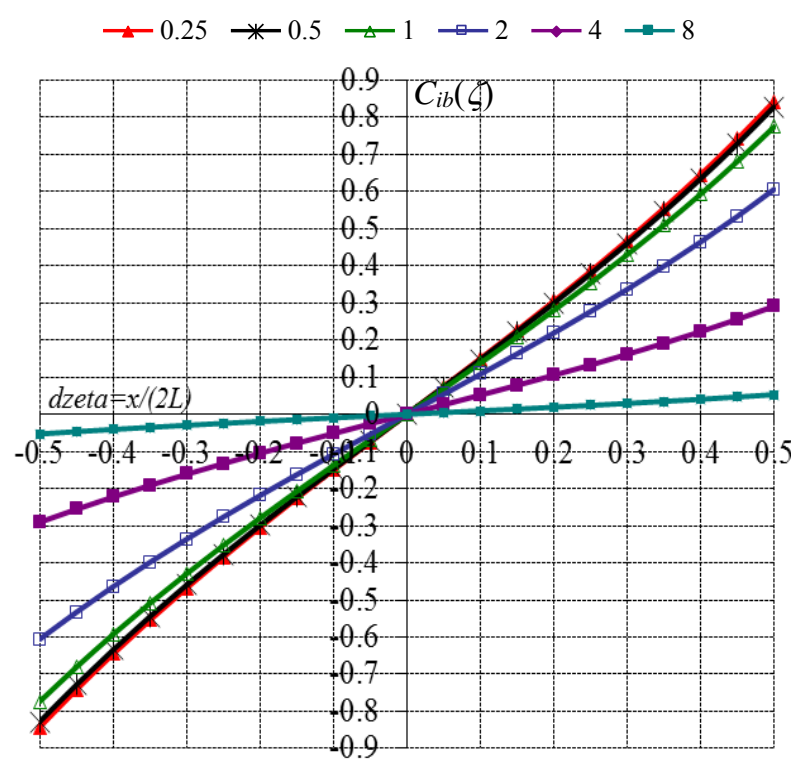

Fig. 3: The function $C_{i b}(\zeta)$ of the impulsive bottom pressures distribution of liquid for various reservoir slenderness parameter $\gamma$ of liquid filling 
The distribution of the hydrodynamic impulsive pressure of the contained liquid domain is given on the bottom of the rectangular tank solid domain by

$p_{i b}(\zeta, t)=C_{i b}(\zeta) \rho H A_{g}(t)$,

$C_{i b}(\zeta)=\frac{\sqrt{3}}{2}\left(\sinh \sqrt{3} \frac{x}{H} / \cosh \frac{\sqrt{3}}{2} \frac{H}{L}\right)$.

\subsection{The hydrodynamic convective pressure}

The hydrodynamic convective pressure of the contained liquid domain is given on the side vertical wall of the rectangular tank solid domain by

$p_{c n w}(\xi, t)=\sum_{n=1}^{\infty} Q_{c n w}(\xi) \rho L A_{c n}(t)$,

$Q_{c 1 w}(\xi)=0.833 \frac{\cosh \left(\xi \frac{1}{2} \sqrt{\frac{5 H}{2 L}}\right)}{\cosh \left(\frac{1}{2} \sqrt{\frac{5 H}{2 L}}\right)}$.

The distribution of the hydrodynamic convective pressure of the contained liquid domain is given on the bottom of the rectangular tank solid domain by

$p_{c n b}(\zeta, t)=\sum_{n=1}^{\infty} Q_{c n b}(\zeta) \rho L A_{c n}(t)$,

$Q_{c 1 b}(\zeta)=2.5\left(\frac{\zeta}{2 L}-\frac{4}{3}\left(\frac{\zeta}{2 L}\right)^{3}\right) \operatorname{sech}\left(\frac{H}{2 L} \cdot \sqrt{\frac{5}{2}}\right)$.

In Eqs. 3-11 gills following

$H, L$ are inner dimensions of liquid filling, Fig. 1,

$\gamma=H / L$ is the liquid slender parameter [-],

$\xi=z / H$ is the vertical dimension [-],

$\zeta=x / L$ is the horizontal dimension on bottom [-], where $x \in\langle-L ;+L\rangle$,

$C_{i w}(\xi)$ is the hydrodynamic impulsive pressure distribution on the side vertical wall of the rectangular tank solid domain [-],

$C_{i b}(\zeta)$ is the hydrodynamic impulsive pressure distribution on the bottom of the rectangular tank solid domain [-],

$Q_{c n w}(\xi)$ is the of the hydrodynamic convective pressure distribution on the side vertical wall of the rectangular tank solid domain for $n$ mode [-],

$Q_{c 1 w}(\xi)$ is the is the of the hydrodynamic convective pressure distribution on the side vertical wall of the rectangular tank solid domain for first mode [-],

$Q_{c n b}(\zeta)$ is the of the hydrodynamic convective pressure distribution on the bottom of the rectangular tank solid domain for $\mathrm{n}$ mode [-],

$Q_{c 1 b}(\zeta)$ is the of the hydrodynamic convective pressure distribution on the bottom of the rectangular tank solid domain for first mode [-],

$A_{g}(t)$ is time-history ground acceleration $\left[\mathrm{ms}^{-2}\right]$,

$A_{c n}(t)$ is time-history acceleration of a single degree of freedom oscillator $\left[\mathrm{ms}^{-2}\right]$ that has the circular frequency $\omega_{c n}$,

$n$ is mode of liquid oscillation, $\rho$ is the density of liquid $\left[\mathrm{kgm}^{-3}\right]$, $g$ is gravitational acceleration $\left[\mathrm{ms}^{-2}\right]$,

$t$ is time [s].

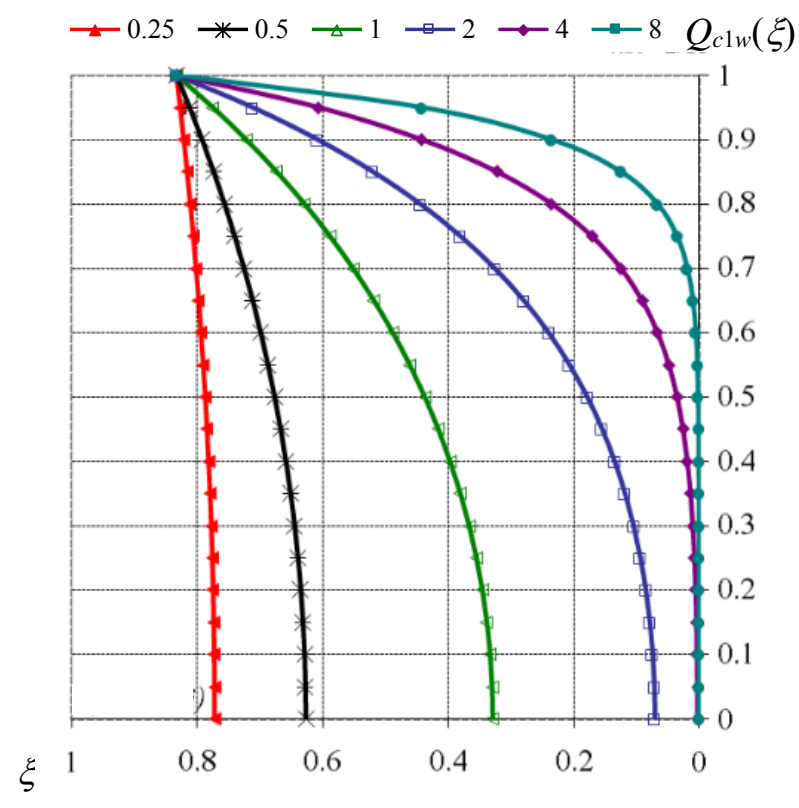

Fig. 4: The function $Q_{c 1 w}(\xi)$ of the convective wall pressures distribution of liquid filling for first mode for various reservoir parameter $\gamma$

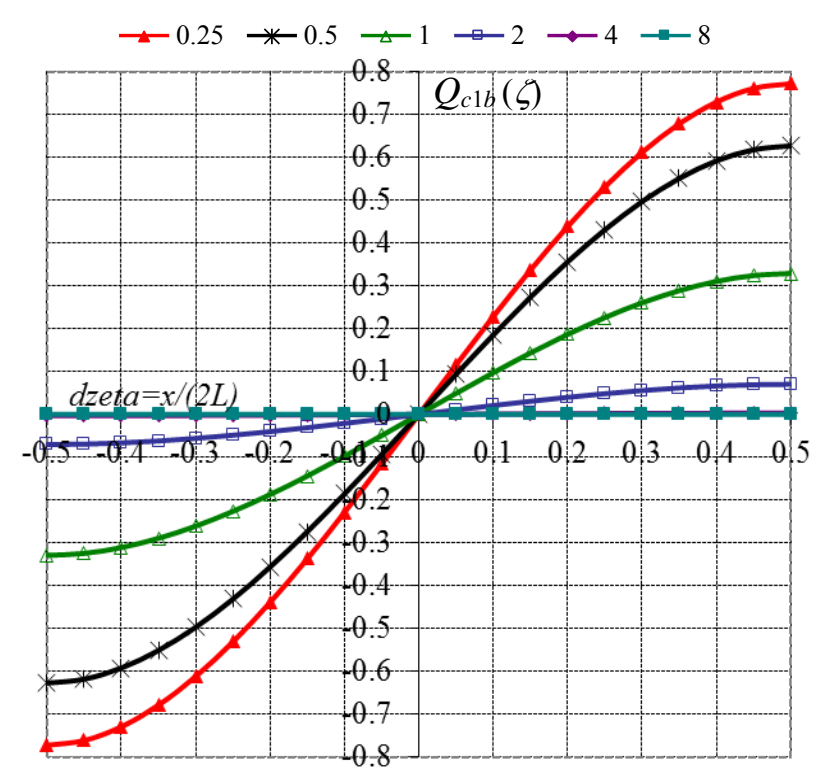

Fig. 5: The function $Q_{c 1 b}(\zeta)$ of the convective bottom pressures distribution of liquid filling for first mode for various reservoir slenderness parameter $\gamma$

Fig. 2-5 show the functions of pressure distribution for various slenderness parameter of liquid filling $\gamma$ : $C_{i w}(\xi)$ is the impulsive vertical wall pressures distribution, $C_{i b}(\zeta)$ is the impulsive bottom pressures 
distribution, $Q_{c 1 w}(\xi)$ is the convective vertical wall pressures distribution, $Q_{c 1 b}(\zeta)$ is the convective bottom pressures distribution.

The natural frequency for the $n^{\text {th }}$ mode is given by Graham and Rodriguez [27,29,33]

$\omega_{n}^{2}=\frac{n \pi g}{2 L} \tanh \left(\frac{n \pi H}{2 L}\right)$.

\section{Experimental Analysis}

The rectangular tank in the shape of the glass hollow block was used to carry out the experiment. The inside dimensions of the tank were: the length $L 39.2$ $\mathrm{cm}$, the height $H_{\text {wall }} 19.2 \mathrm{~cm}$ and the width $B 24.2 \mathrm{~cm}$. The height $H$ represents the maximum dimension of possible full filling with liquid. The vertical wall thickness of the tank was $3.8 \mathrm{~mm}$ and the thickness of the tank bottom was $5 \mathrm{~mm}$. The transparent square grid with the raster size $1 \mathrm{~cm}$ was mounted on the tank front side, the largest side, for the possibility of better video documentation of the liquid movement, see Fig. 6.

The liquid filling was water $-\mathrm{H}_{2} \mathrm{O}$ by using the minimum amount of potassium permanganate, chemically $2 \mathrm{KMnO}_{4}$. The water was acquired the light purple colour for better possibilities of the recording the shape of the liquid. The liquid filling with the filling of height $H=15 \mathrm{~cm}$ was considered for the analysis of this paper. The filling of the rectangular tank with the water was excited by horizontal harmonic motions

$$
x_{f}=A \cdot \sin (2 \pi f t)
$$

where $f$ is the excitation frequency $[\mathrm{Hz}]$, and $A$ is the excitation amplitude $[\mathrm{m}]$ that has the value $0.5 \mathrm{~cm}$ or $1 \mathrm{~cm}$, respectively.

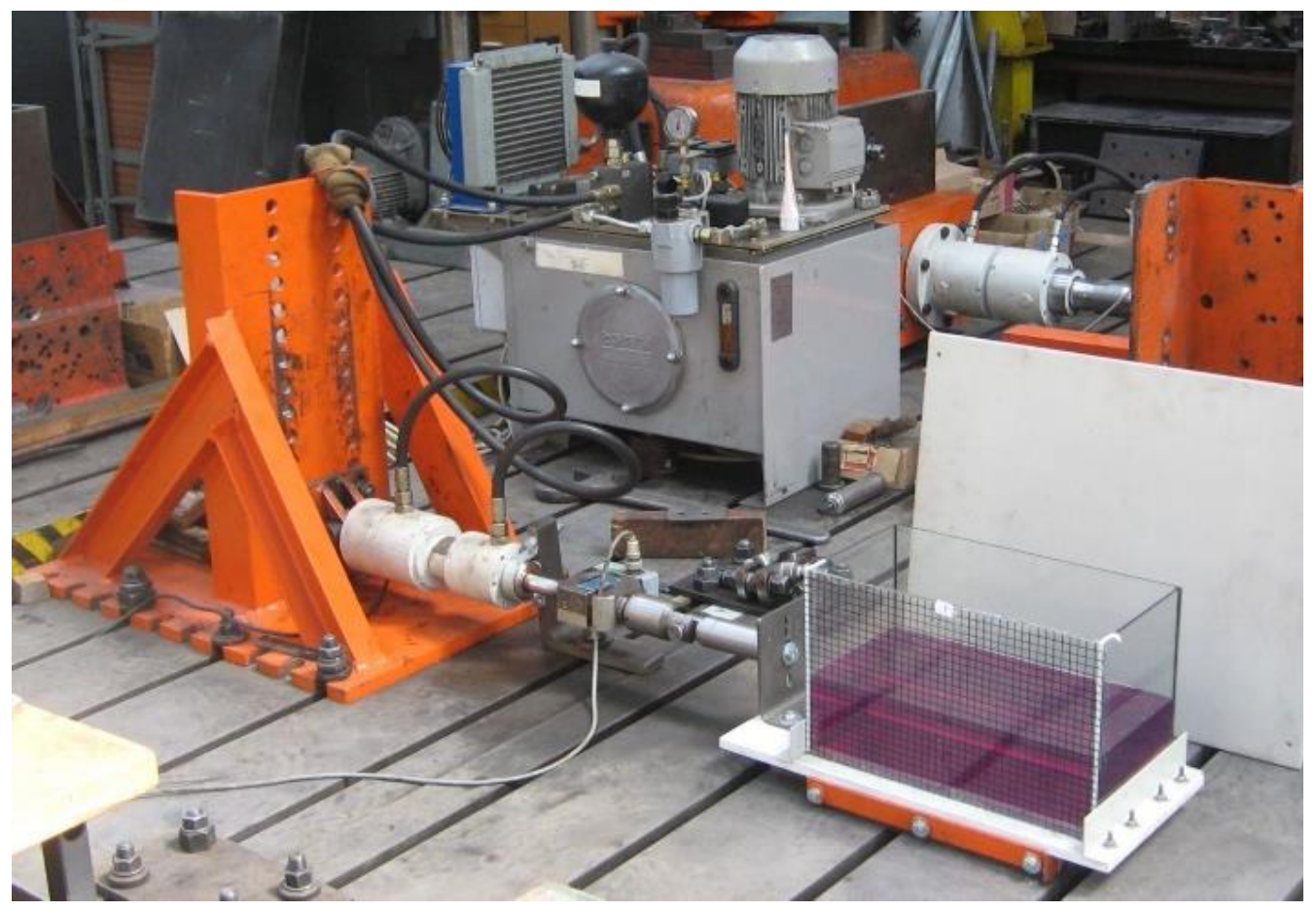

Fig. 6: View of the experiment workplace and test equipment

The movement was realized by using of hydraulic pulsator ULBRICHT HZ UHN315-R-6-50/28$100=$ GR-MA-V-WMS, in direction of the longest tank bottom side, Fig. 6 . The pulsator was controlled by the personal computer, the control screen was presented in Fig. 7.

The digital camera Panasonic SDR-H250EP-S was used for recording in the experiment.

The first ten frequencies of liquid filling with dimensions $39.2 \mathrm{~cm} \times 24.2 \mathrm{~cm} \times 15 \mathrm{~cm}$, documented in Table 1, were calculated by Eq. (13).

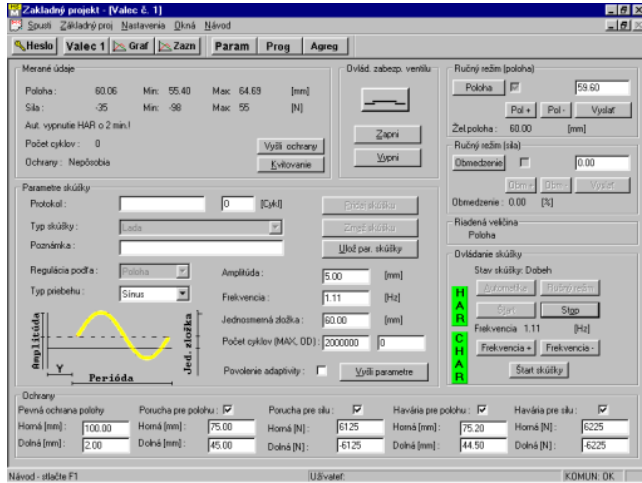

Fig.7: View of the PC control screen 
Table 1: The frequencies of liquid filling

\begin{tabular}{|c|c|}
\hline number & Frequency $\boldsymbol{f}$ \\
\hline 1. & $1.30 \mathrm{~Hz}$ \\
2. & $1.99 \mathrm{~Hz}$ \\
3. & $2.45 \mathrm{~Hz}$ \\
4. & $2.83 \mathrm{~Hz}$ \\
5. & $3.17 \mathrm{~Hz}$ \\
\hline
\end{tabular}

\begin{tabular}{|c|c|}
\hline number & Frequency $\boldsymbol{f}$ \\
\hline 6. & $3.47 \mathrm{~Hz}$ \\
7. & $3.75 \mathrm{~Hz}$ \\
8. & $4.00 \mathrm{~Hz}$ \\
9. & $4.25 \mathrm{~Hz}$ \\
10. & $4.48 \mathrm{~Hz}$ \\
\hline
\end{tabular}

a)

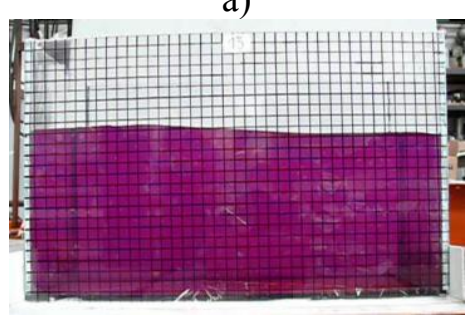

$A=1.0 \mathrm{~cm}, f=0.8 \mathrm{~Hz}$

d)

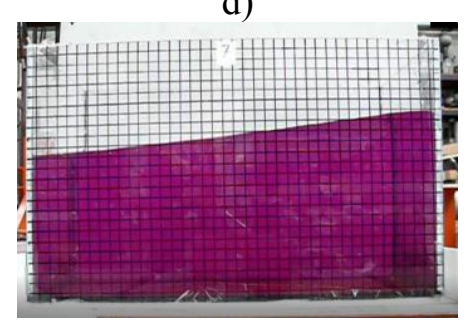

$A=0.5 \mathrm{~cm}, f=1.21 \mathrm{~Hz}$

g)

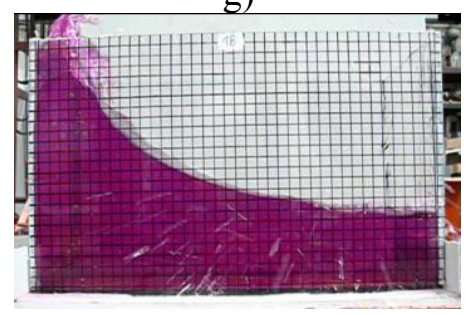

$A=1.0 \mathrm{~cm}, f=1.2 \mathrm{~Hz}$ b)

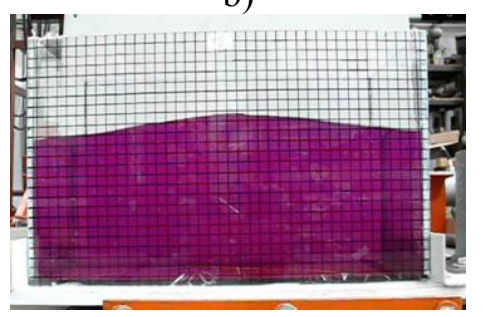

$A=1.0 \mathrm{~cm}, f=1.0 \mathrm{~Hz}$

e)

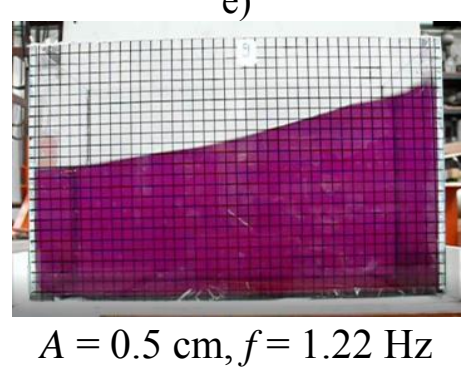

h)

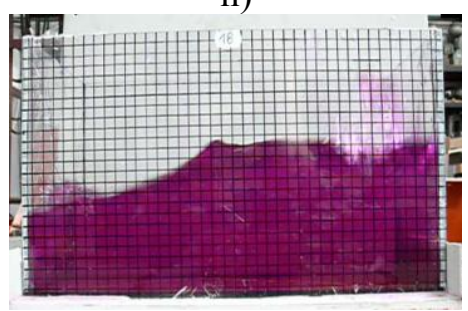

$A=1.0 \mathrm{~cm}, f=1.2 \mathrm{~Hz}$ c)

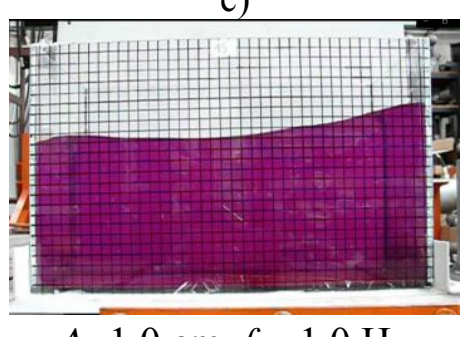

$A=1.0 \mathrm{~cm}, f=1.0 \mathrm{~Hz}$

f)

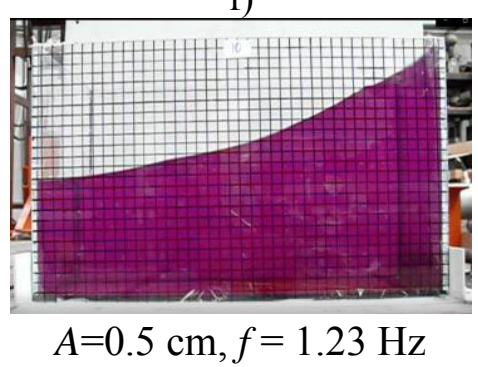

i)

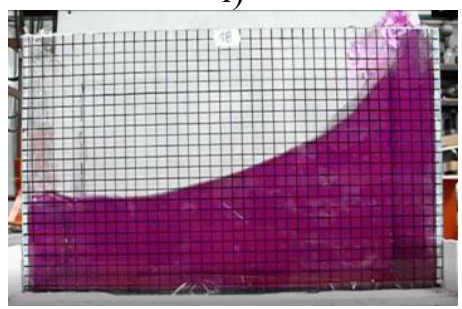

$A=1.0 \mathrm{~cm}, f=1.2 \mathrm{~Hz}$

Fig. 8: The phenomena of sloshing for various excited amplitudes and frequencies

Fig. 8 documents the phenomena of the sloshing for various excited amplitudes and frequencies. The monitored wave heights were different, they were depended mainly on the excited frequency, and on the amplitude also. If the liquid filling was excited by the frequency close to the natural frequency, then large waves were formed until the liquid flushed out.
Fig. 8a), Fig. 8b), and Fig.8c) show the relatively calm free surface of the liquid with the small waves. Fig. 8d), Fig. 8e), and Fig.8f) present the large wave of the liquid free surface. These waves could be measured and recorded. The maximum measurement height of the liquid wave was $15 \mathrm{~cm}$ in this experiment. Fig. 8g), Fig. 8h), and Fig.8i) document 
the markedly splashing state of the liquid. The fluid flushes out from the tank, the fluid was spilled out of the tank. Thus, the measurement of the wave heights was not possible, and this condition is documented with the wave height $16 \mathrm{~cm}$ from the original surface in Fig. 9.

Only frequencies up to the value of the first natural frequency were tested in this experiment.

The peak waves of liquid for $15 \mathrm{~cm}$ water filling were presented in Fig. 9 in depending on frequency, see

a)

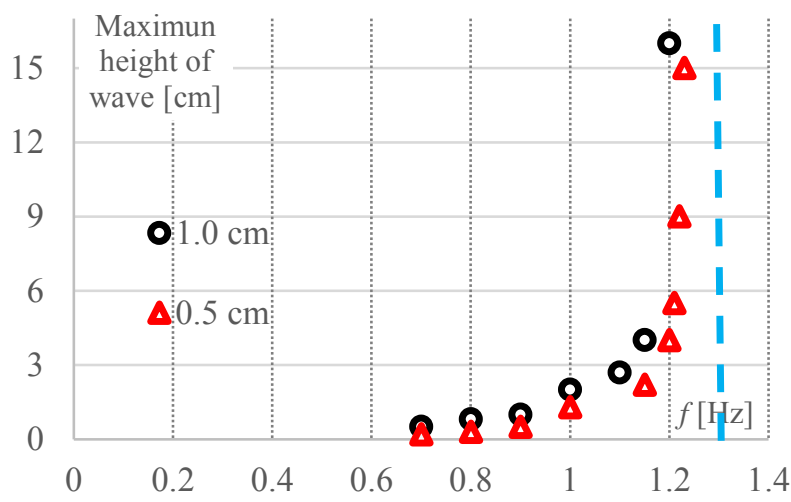

Fig. 9a, and in depending on acceleration, see Fig. 9b. The peak waves of liquid excited with amplitude $0.5 \mathrm{~cm}$ is documented with red triangle, and with amplitude $1.0 \mathrm{~cm}$ with black circle. The first frequency of the $15 \mathrm{~cm}$ height rectangular tank liquid filling is $f_{1}=1.30 \mathrm{~Hz}$, see Table 1 , and the first frequency is also shown by vertical dash light blue line in Fig. 9a. The culmination of the waves close to the first frequency is evident. The next second and higher modes (shapes) were not monitored.

b)

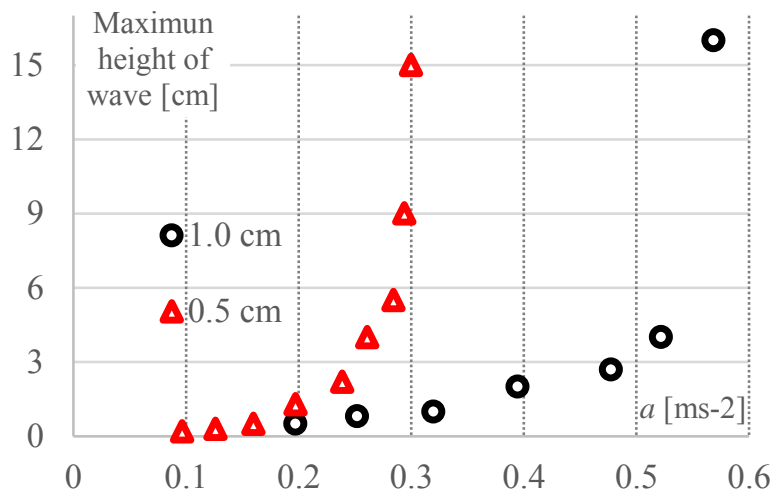

Fig. 9: The peak values of liquid waves in rectangular liquid domain excited with amplitude $0.5 \mathrm{~cm}$ and $1.0 \mathrm{~cm}$ for $15 \mathrm{~cm}$ liquid filling as a) the function of frequency $f[\mathrm{~Hz}]$ and b) as the function of acceleration $a\left[\mathrm{~ms}^{-2}\right]$

\section{Numerical Analysis}

The numerical analysis was simulated for rectangular liquid filling $\left(\mathrm{H}_{2} \mathrm{O}\right)$ with horizontal dimension $192 \mathrm{~mm} \times 392 \mathrm{~mm}$ and hight $150 \mathrm{~mm}$ contained in rectangular glass container. The liquid filling contained in glass tank was excited by the horizontal harmonious motion with amplitude $5 \mathrm{~mm}$ and frequency $f=1 \mathrm{~Hz}$.

The Finite Element Method (FEM) was used to the impeccable rigid container (vertical walls and bottom) in numerical simulation. For that, we consider the 2D numerical model of the dimension $392 \mathrm{~mm} \times 150 \mathrm{~mm}$, see Fig. 1, and the liquid boundary conditions of the liquid domain that are outlined as:

- the free surface - upper border,

- "BOUNDARY-CONDITION WALL", it is the fictitious rigid wall with the possibility of rigid solids movement - side vertical and bottom borders [34].

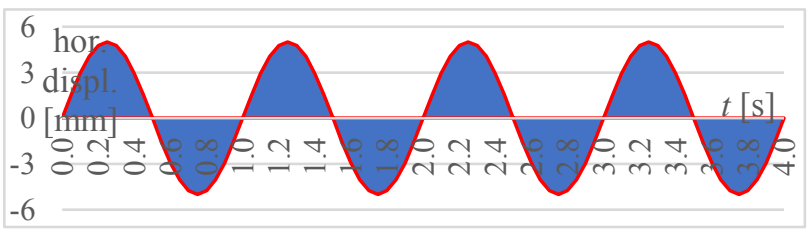

Fig. 10: The excited horizontal displacement
The frequency of the simulated horizontal harmonious excitation was $f=1 \mathrm{~Hz}$ and the excite amplitude was $5 \mathrm{~mm}$. The record of the input excited horizontal displacement was shown for numerical simulation of the problem in Fig. 10.

\section{Results and conclusion}

The results of numerical simulation were obtained for first four seconds of movement.

The peak value of the hydrostatic and total pressure arises in the bottom of the liquid domain. The value of the hydrostatic pressure is given by known analytical solution: $\rho \cdot g \cdot H=1000 \cdot 9.81 \cdot 0.15$ and the peak value of the hydrostatic pressure is also 1471.5 $\mathrm{Pa}$.

The peak value of the total pressure arises in the left or the right bottom edge of the liquid domain. The total pressure of the liquid filling given by the numerical simulation using FEM is $1554 \mathrm{~Pa}$.

Fig. 11 documents of the pressure distribution and the shape of liquid domain in time $2.775 \mathrm{~s}$, it is the time when the peak value of liquid pressure arises. The peak value of liquid pressure arises in bottom edge nodes, in the left bottom edge node - it is 75 (named LBE), and in right bottom edge node - it is 51 (named RBE). The node 75 (LBE) is documented by small triangle in Fig. 11. 


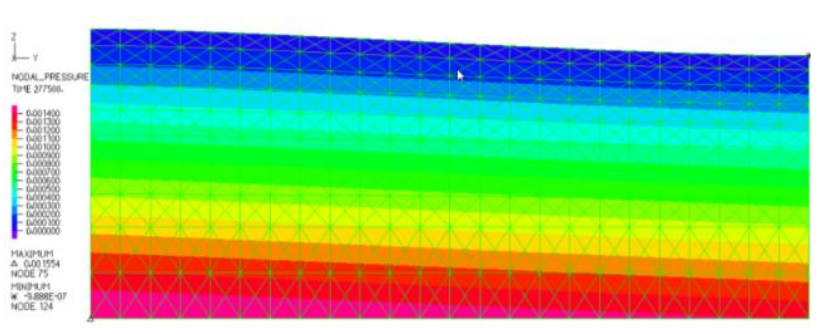

Fig. 11: The pressure distribution and the shape of liquid domain in time $2.775 \mathrm{~s}$

Fig. 12 is shown the shapes and the pressure distributions of the liquid domain a) in time $1.300 \mathrm{~s}$ and b) $2.775 \mathrm{~s}$, respectively. The liquid filling during the horizontal movement of the tank is alternately loaded once on one side and then on the other side: right side Fig. 12a), and left side Fig. 12b). Related to this, the changes of the pressure in the liquid domain, and the movement of the originally calm liquid filling level (origin of waves).

a)

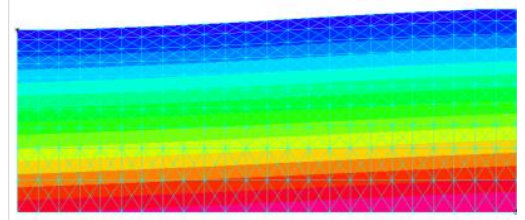

b)

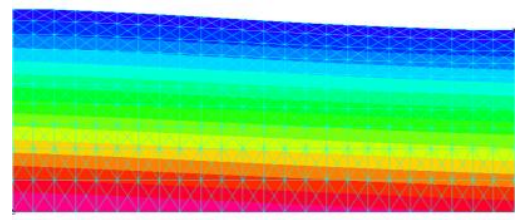

Fig. 12: The pressure distribution of moving liquid domain in time $1.300 \mathrm{~s}$ and $\mathrm{b}$ ) in time $2.775 \mathrm{~s}$ of the liquid domai

a)

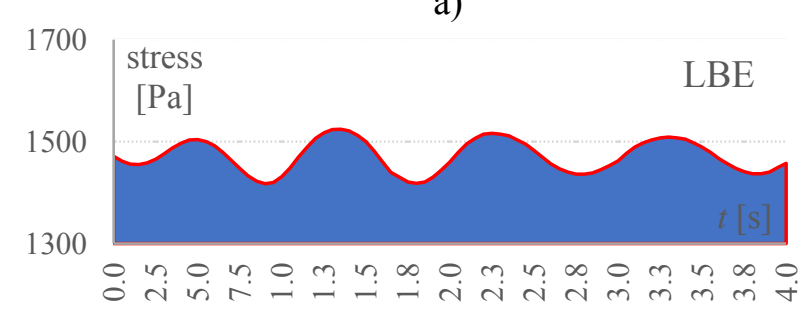

b)

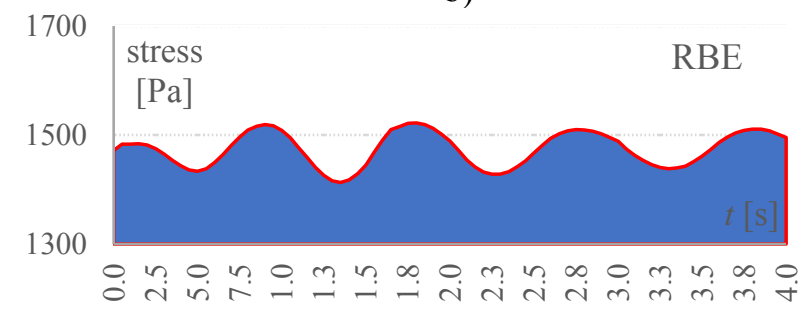

c)

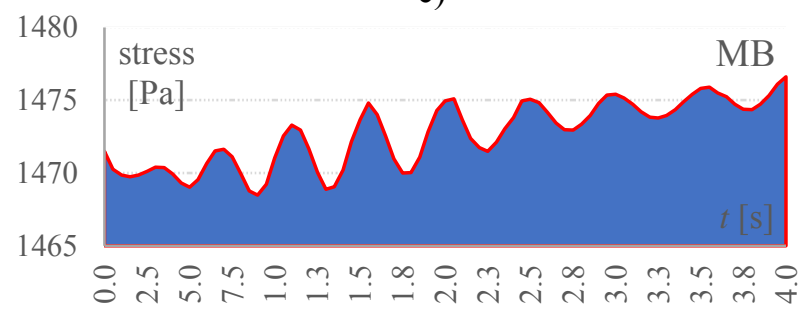

Fig. 13: The time-depended response of the liquid pressure in node a) LBE, in node b) RBE, in node c) MB

The next Fig. 13a-c show the time-depended response of the liquid domain - the total liquid pressure:

a) in the LBE node of the liquid domain,

b) in the RBE node of the liquid domain,

c) in the MB node, the middle bottom node of the liquid domain.

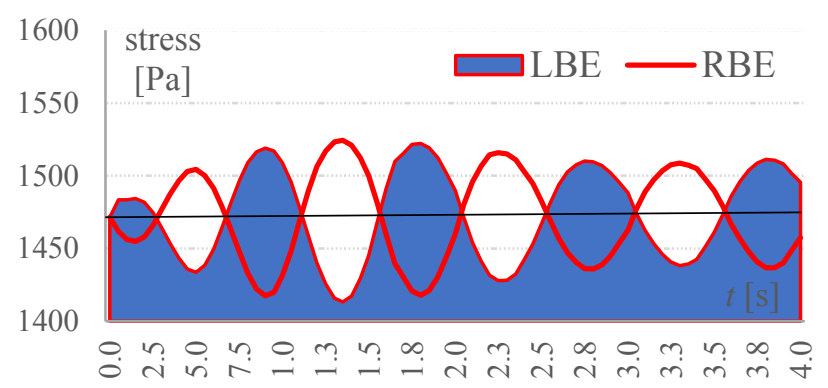

Fig. 14: Comparison of the time-depended response of the total liquid pressure in LBE and RBE

The comparison of the time-depended response - the total pressure of the liquid domain in nodes LBE and $\mathrm{RBE}$ is presented in Fig. 14. Obviously, the timedependent responses of liquid domain - the pressures are completely asymmetric in LBE and RBE nodes.

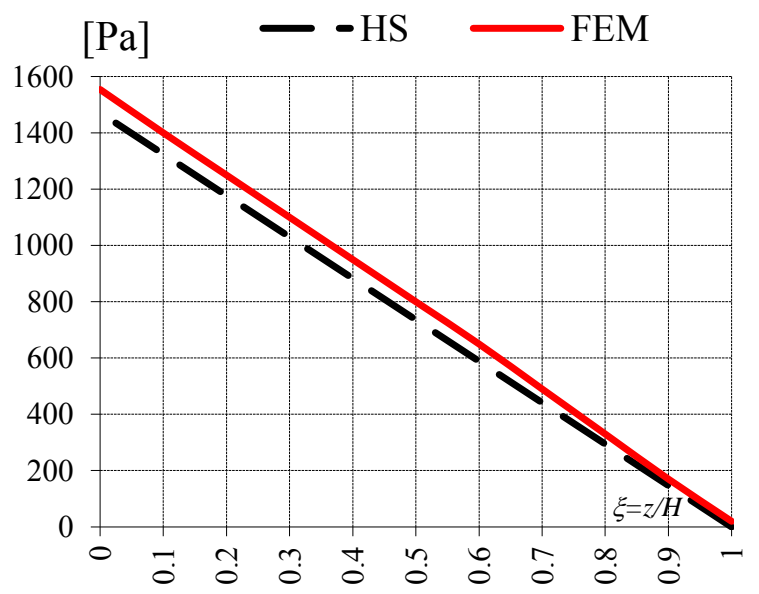

Fig. 15: Comparison of the pressures distribution (hydrostatic pressureand peak total pressure) on vertical side of liquid domain 
Fig. 15 documented the comparison of the pressure distribution on the vertical side of the liquid domain, i.e. the total pressure which ask on the vertical wall of the tank. The dashed black line represents the hydrostatic pressure, and the red line represents the peak value of the total moved liquid domain pressure. The total pressure was obtained by FEM. The level " 0 " means bottom of the liquid domain on vertical side and " 1 " means free surface level of the liquid domain on vertical side.

a)

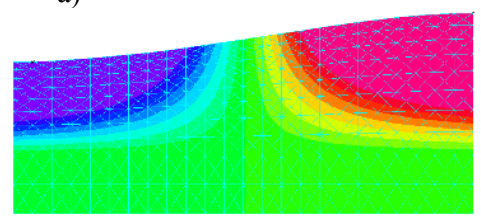

b)

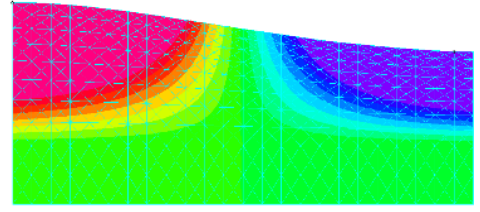

Fig. 16: The shape of liquid domain and the vertical displacement a) in time $1.325 \mathrm{~s}$ and b) in time $1.80 \mathrm{~s}$

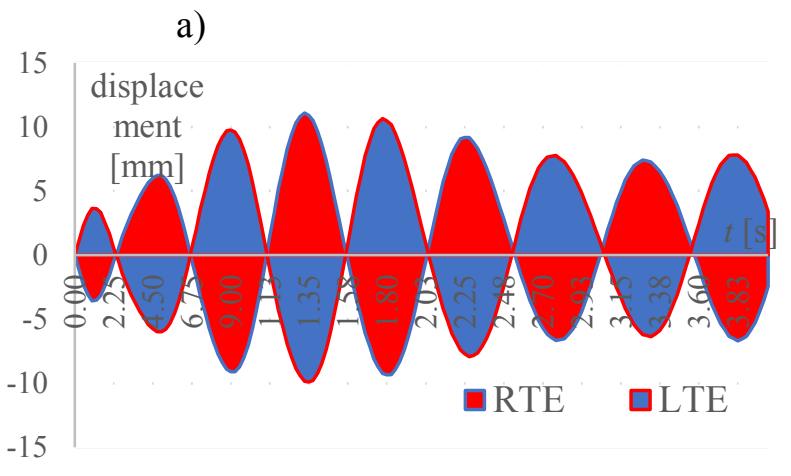

b)

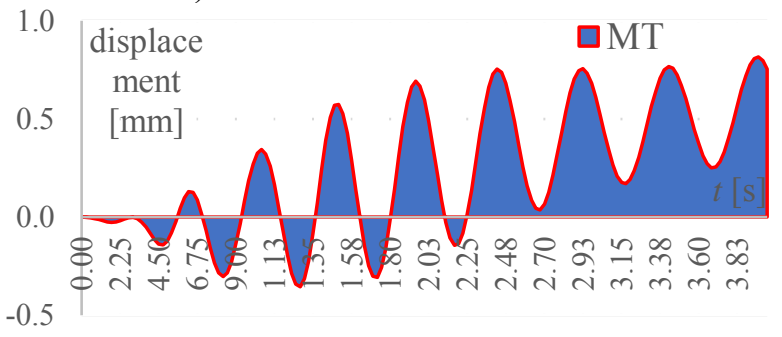

Fig. 17: The liquid vertical displacement of liquid domain a) for RTE and LTE nodes in time $1.325 \mathrm{~s}$ and $\mathrm{b}$ ) for MT node in time $1.80 \mathrm{~s}$

Fig. 16 shows the shape and the vertical displacement of liquid domain. Fig. 16a) documents the peak vertical displacement response of the liquid domain on right side, it is in time $1.325 \mathrm{~s}$ and Fig. 16b) shows the peak vertical displacement on left side, it is in time $1.80 \mathrm{~s}$.

Fig. 17a) shows the comparison of the time-depended response - the vertical displacement of the liquid domain in the nodes: LTE (left top edge) of the free surface and in RTE (right top edge) of the free surface, respectively. It is seen that the timedepended responses of the liquid domain - the vertical displacements are completely asymmetric. The time-depended response of the liquid domain (the vertical displacement) in the nodes LTE and RTE correlates about the zero value, the zero value is the original free surface of the liquid domain in time of the quit situation.

Fig. 17b) documents the time-depended response of the liquid domain - the vertical displacement in the node MT (middle top) of the free surface.

\section{Conclusion}

The dynamic behaviour of the liquid filling in the moved rectangular reservoir due to the horizontal harmonic motion was analysed in this paper. The rectangular liquid filling (water) with the height of filling $15 \mathrm{~cm}$ was considered and it was excited by the horizontal harmonious motions with amplitude 5 $\mathrm{mm}$ and frequency $f=1 \mathrm{~Hz}$.

The experimental results confirmed the analytical calculated value of the first frequency. The experimental results confirmed that the liquid filling was excited at the frequency close to the natural frequency, then the large waves were formed until the liquid flushed out.

The numerical solution documents the numerical simulation possibility of quitter state of the moved liquid domain by using FEM. The peak values of the total liquid pressure given by the numerical simulation document the increase of the pressure in case of moving of the liquid filling. The pressure highest values occur at the bottom of liquid domain. The numeric analysis documents that the original free surface does not remain calm. Due to the horizontal exciting starts the swaying of the free surface to the large waves until the liquid flushed out, it is depended on the shape of the liquid domain and the excited frequencies of the liquid filling.

This study is one of the contributions to the analysis of the interaction between the tank and the liquid. The knowledge of the liquid effect during the liquid storage tank movements, as well as the frequency properties of the tank-liquid systems are the basis for good analysis and design of structures / devices resistant to the hydrodynamic action of the liquid charge. 


\section{Acknowledgment}

Preparation of the paper was supported by the Scientific Grant Agency of the Ministry of Education of Slovak Republic and the Slovak Academy of Sciences under Project VEGA 1/0374/19.

\section{References}

[1] H. N. Abramson, The dynamic behavior of liquids in moving containers. NASA SP-106, National Aeronautics and Space Administration, Washington, D. C., 1966.

[2] P. Pal, Sloshing of Liquid in Partially Filled Container - An Experimental Study. International Journal of Recent Trends in Engineering. Vol.1, No. 8, 2009, pp. 1-5.

[3] L. Khezzar, A. Seibi, A. Goharzadeh, Water sloshing in Rectangular Tanks - An Experimental Investigation \& numerical simulation. International Journal of Engineering, Vol. 3, No. 2, 2009, pp. 174-184.

[4] R. Zhou, M. Vargalla, S. Chintalapati, D. Kirk, H. Gutierrez, Experimental and Numerical Investigation of Liquid Slosh Behavior Using Ground-Based Platforms. Journal of Spacecraft and Rockets, Vol. 49, No. 6, 2012, pp. 11941204.

[5] K. Kotrasová, Dynamic Behavior of Fluid Rectangular Container. International Journal of Mechanics, Vol. 12, 2018, pp.170-177.

[6] M. J. Jhung, S.-S. Kang, Fluid effect on the modal characteristics of a square tank. Nuclear Engineering and Technology. Vol. 51, 2019, pp. 1117-1131.

[7] M. F. Younes, Y. K. Younes, Experimental investigation for liquid sloshing in baffled rectangular tanks. International journal of scientific \& technology research. Vol. 4, No. 12, 2015, pp. 57-61.

[8] M. Ha, D. Kim, H. I. Choi, Ch. Cheong, S. H. Kwon, Numerical and experimental investigations into liquid sloshing in a rectangular tank. Advances in Civil, Environmental, and Materials Research (ACEM' 12), 2012, pp. 3546-3553.

[9] K. Kotrasova, Sloshing of Liquid in Rectangular Tank. Advanced Materials Research. No. 969, 2014, pp. 320-323.

[10] A. Colagrossi, C. Lungi, M. Greco, O. M. Faltisen, Experimental and numerical investingation of $2 \mathrm{D}$ sloshing with slamming. Advances in Civil, Environmental, and Materials Research (ACEM' 12), 2012, pp. 1-6.

[11] K. Kotrasova, E. Kormanikova, The study of seismic response on accelerated contained fluid.
Advances in Mathematical Physics. Vol. 2017, 2017, pp. 1-9.

[12] W. Maschek, A. Roth, M. Kirstahler, L. Meyer, Simulation Experiments for Centralized Liquid Sloshing Motions. Karlsruhe, 1992, pp. 1-60.

[13] M. Mocilan, M, Zmindak, P. Pastorek, Dynamic analysis of fuel tank. Procedia Engineering. 136, 2016, pp. 45-49.

[14] K. Kotrasova, E. Kormanikova, Hydrodynamic Analysis of Fluid Effect in Rigid Rectangular Tank Due to Harmonic Motion. Key Engineering Materials. Vol. 635, 2015, pp. 147150.

[15] J. H. Jung, H. S. Yoon, C. Y. Lee, Effect of natural frequency modes on sloshing phenomenon in a rectangular tank. International Journal of Naval Architecture and Ocean Engineering. Vol. 7, 2015, pp. 580-594.

[16] J. Kralik, "Risk-based safety analysis of the seismic resistance of the NPP structures," EURODYN 2011 - 8th International Conference on Structural Dynamic, 2011, pp. 292-299.

[17] K. Kotrasova, E. Kormanikova, A Study on Sloshing Frequencies of Liquid-Tank System. Key Engineering Materials. Vol. 635, 2015, pp. 22-25.

[18] K. Kotrasova, I. Grajciar, Dynamic Analysis of Liquid Storage Cylindrical Tanks Due to Earthquake. Advanced Materials Research. No. 969, 2014, pp. 119-124.

[19] M.-A. Xue, J. Zheng, P. Lin, Numerical Simulation of Sloshing Phenomena in Cubic Tank with Multiple Baffles. Journal of Applied Mathematics. Vol. 2012, 2012, pp. 1-22.

[20] F. Viola, F. Gallaire, B. Dollet, Sloshing in a Hele-Shaw cell: experiments and theory. Journal of Fluid Mechanics. pp. 1-12.

[21] K. Kotrasová, Simplified seismic analysis of rectangular tank considering fluid-structure-soil interaction. AIP Conference Proceedings. Vol. 1978, 2018, pp. 1-4, Article number 150009.

[22] J. Melcer, M. Kudelcikova, Frequency characteristics of a dynamical system at force excitation. MATEC Web of Conferences. Vol. 107, 2017, pp. 1-7.

[23] M. Krejsa, P. Janas, V. Krejsa, "Software application of the DOProC method," International Journal of Mathematics and Computers in Simulation, vol. 8, no. 1, 2014, pp. 121-126.

[24] J. Habenberger, J. Schwarz, Damping effects of the fluid in cylindrical liquid storage tanks. Earthquake Engineering and Structural Dynamics. 2005. 
[25] V. Michalcova, L. Lausová, Numerical approach to determination of equivalent aerodynamic roughness of Industrial chimneys. Computers and Structures. Vol. 207, 2017, pp. 187-193.

[26] H. V. Shreeharsha, S.G. Shivakumar, S.G. Mallikarjun, Simulation of Sloshing in Rigid Rectangular Tank and a Typical Aircraft. Journal of Aeronautics \& Aerospace Engineering. Vol. 6, No. 2, 2017, pp. 1-9.

[27] EN 1998-4: 2006 Eurocode 8. Design of structures for earthquake resistance. Part 4: Silos, tanks and pipelines. CEN, Brussels, 2006.

[28] O.R. Jaiswal, D.C. Rai, S.K. Jain, Review of code provision on design seismic forces for liquid storage tanks. IITK-GSDMA-EQ01V1.0. Kanpur, Indian Institute of Technology Kanpur.

[29] G. W. Housner, Earthquake pressures on fluid containers. California institute of technology, Pasadena California, 1954.
[30] L. Meirovitch, Computational Methods in Structural Dynamics. Sijthoff \& Noordhoff, 1980.

[31] K. Kotrasova, E. Kormanikova, A case study on seismic behavior of rectangular tanks considering fluid - Structure interaction. International Journal of Mechanics. Vol. 10, 2016, pp. 242-252.

[32] K. Kotrasova, Study of hydrodynamic pressure on wall of tank. Procedia Engineering. Vol. 190, 2017 pp. 2-6.

[33] K. Kotrasová, I. Grajciar, E. Kormaníková, A Case Study on the Seismic Behavior of Tanks Considering Soil-Structure-Fluid Interaction. Journal of Vibration Engineering and Technologies. Vol. 3, No. 3, 2015, pp. 315-330. ISSN 2321-3558.

[34] Theory and Modeling Guide, Volume I: ADINA. December 2012.

\section{Creative Commons Attribution License 4.0 (Attribution 4.0 International, CC BY 4.0)}

This article is published under the terms of the Creative Commons Attribution License 4.0 https://creativecommons.org/licenses/by/4.0/deed.en_US 